Bangladesh J. Bot. 48(2): 359-366, 2019 (June)

\title{
DEVELOPMENT AND CHARACTERIZATION OF INTRASPECIFIC HYBRIDS DERIVED FROM CUCUMIS MELO L.
}

\author{
BR Choudhary*, Dhurendra Singh and PL SaroJ \\ ICAR-Central Institute for Arid Horticulture, Bikaner (Rajasthan)-334 006, India
}

Keywords: Cucumis melo, Intraspecific hybridization, Characterization, Segregating population

\begin{abstract}
An intraspecific hybridization programme among Cucumis species involving eight genetically diverse parents of C. melo L. varietal group viz., IC-0599709, Punjab Sunehri, Pusa Madhuras, Kashi Madhu (C. melo L.), AHK-119 (C. melo var. callosus), AHLM-2 (C. melo var. utilissimus), AHS-82 (C. melo var. momordica) and Arya-1 (C. melo var. chate) were undertaken. Among the dessertic $\mathrm{F}_{1}$ hybrids, IC-0599709 $\times$ Punjab Sunehri resulted best with respect to first fruit harvest (73.33 days), fruit weight (938.00 g), fruit diameter $(11.90 \mathrm{~cm})$, flesh thickness $(3.07 \mathrm{~cm})$, total soluble solids $(9.73 \%)$ and flesh colour (salmon orange). $\mathrm{F}_{2}$ population of AHK-119 $\times$ Kashi Madhu produced maximum number of marketable fruits per plant (11.2) weighing $350.00 \mathrm{~g}$ in 86.1 days. It was also found to be tolerant to high temperature. The $\mathrm{F}_{2}$ population of AHK-119 $\times$ Kashi Madhu were found to be tolerant to high temperature. The existing variability among the parents, intra-specific crosses and segregating generations for fruit (size, shape, colour), yield and quality parameters could be exploited to develop new segregants with desirable traits.
\end{abstract}

\section{Introduction}

Melon (Cucumis melo L.) is an economically important annual species cultivated all over the world. Among the genera of the Cucurbitaceae, the Cucumis contains two species of great economic importance. Cucumis melo L., the muskmelons $(2 \mathrm{n}=24)$, and C. sativus L., the cucumbers $(2 \mathrm{n}=14)$, are widely grown for their edible fruits or seeds in different parts of India. Nearly 40 species of the genus Cucumis have been documented (Whitaker and Davis 1962). C. melo is extremely variable and comprised of wild and cultivated varieties, the latter including sweet 'dessert' melons, as well as non-sweet forms that are consumed raw, pickled or cooked. The genus Cucumis is unique in India as all the species bear edible fruits esteemed for their taste and nutritive value. In India, the main states cultivating melons are Rajasthan, Uttar Pradesh, Bihar, Delhi, Haryana, Punjab and Kerala.

The species $C$. melo is a large polymorphic taxon, encompassing a large number of botanical and horticultural varieties or groups agrestis, cantalupensis, inodorus, conomon, dudaim, flexuosus and momordica (Munger and Robinson 1991). Intraspecific hybridization is used to improve crops by transferring desirable horticultural traits (Singh et al. 2013) and some specific traits such as pest and stress resistance from wild species to cultivated species (Whitaker and Davis 1962). Great morphological variation exists in fruit characteristics such as size, shape, colour, texture and composition, and $C$. melo is therefore, considered the most diverse species of the genus (Jaffery 1980, Stepansky et al. 1999). In India, wide genetic diversity in melons has been reported by Sheshadri and More (2002), Dhillon et al. (2007), Choudhary et al. (2012) and Malik et al. (2014). Melons may be andromonoecious, gynoecious, gynomonoecious, hermaphrodite or monoecious. Muskmelon is predominantly andromonoecious in sex expression however, monoecious sex form is also found in natural populations (Choudhary et al. 2015) which

*Author for correspondence: <choudharybr71@gmail.com>. 
could be utilized in hybrid seed production without emasculation. The extensive variation found in C. melo and their crossability to each other has led breeders to propose intraspecific hybridization. An exchange of genes between the cultivated sub-species of $C$. melo would open a vast potential resource of variability for commercial exploitation. This group of melons has not been exploited in crop improvement programme despite having several desirable traits (Pandey et al. 2010). The creation of variability is pre-requisite for any crop improvement programme. Keeping in view, the intraspecific crosses utilizing eight genetically diverse inbred lines of C. melo varietal group were hybridized and evaluated for different horticultural traits.

Therefore, the present study was designed involving commonly cultivated melons in India to determine the potential of $F_{1}$ hybrids and segregating generations derived through intraspecific hybridization of the genetically diverse melon groups and selection of high temperature tolerant segregants in subsequent generations.

\section{Materials and Methods}

The hybridization experiment comprised of eight diverse inbred lines comprising IC0599709, Punjab Sunehri, Pusa Madhuras, Kashi Madhu of C. melo L., AHK-119 of C. melo var. callosus, AHLM-2 of C. melo var. utilissimus, AHS-82 of C. melo var. momordica, Arya-1 of $C$. melo var. chate. Hand pollination was carried out during summer season of 2014 at Research Farm of ICAR-Central Institute for Arid Horticulture, Bikaner, Rajasthan, India located at $28^{\circ} \mathrm{N}$ latitude, $73^{\circ} 18^{\prime} \mathrm{E}$ longitude at an altitude of $234.84 \mathrm{~m}$ above sea level. Fresh pollen was used for all the combinations and crossing was done during morning hours. The resultant hybrids and parents were evaluated during summer season of 2015 and 2016 in RBD with three replications. The hybrids were self pollinated to derive $F_{2}$ populations. The resultant $F_{2}$ families were evaluated during summer 2016 without randomization. One hundred plants of each $\mathrm{F}_{2}$ population were raised and individual $\mathrm{F}_{2}$ plants have been treated as an identical genotype (family). The soil of experimental field was loamy sand with a $\mathrm{pH}$ of 8.7 , EC $0.20 \mathrm{dS} / \mathrm{m}$ and organic carbon $0.07 \%$. The crop was raised on drip system maintaining row to row distance $2.5 \mathrm{~m}$ and plant to plant 0.60 $\mathrm{m}$. Plants were fertilized and sprayed against pests and pathogens according to recommended agronomic practices.

The data were recorded on five randomly selected plants from each replication for days to produce 50\% pistillate flowering, node at which first pistillate flower appeared, days to first fruit harvest, fruit weight $(\mathrm{g})$, fruit length $(\mathrm{cm})$, fruit diameter $(\mathrm{cm})$, flesh thickness $(\mathrm{cm})$, number of marketable fruits/ plant and TSS (\%). Fruit traits viz., weight, length, diameter and flesh thickness were recorded at marketable stage. Diameter of fruits was measured with the help of Digital Vernier Caliper (MITU-TOYO, $300 \mathrm{~mm}, 0.01 \mathrm{~mm}$ reading capacity). TSS was tested with the help of digital hand Refrectometer (ATAGO-Japan) $0-53 \%$ readability at ripening stage. Sex expression was recorded at full flowering stage and flesh colour at ripening stage. Fruits were tested at tender stage and again at ripening stage for bitterness. The recorded data were statistically analysed using the INDOSTAT statistical package (Indostat Services, Hyderabad). The data of $F_{1}$ hybrids were recorded on five randomly selected plants from each replication. In $F_{2}$ families, data on each and every plant has been recorded.

\section{Results and Discussion}

The data presented on flowering, growth, yield and quality attributes of parents showed significant difference (Table 1). Among the parents, AHS-82 took minimum days to produce $50 \%$ pistillate flowering (41.00 days) followed by AHLM-2 (42.33 days) while Punjab Sunehri took maximum time (57.67 days). Node at which first pistillate flower appeared varied from 3.40 (IC- 
0599709) to 6.27 (Arya-1). AHLM-2 was found to be earliest with respect to first harvesting which took 48.20 days whereas, Punjab Sunehri took maximum time ( 92.47 days). The maximum fruit weight was recorded in Kashi Madhu (842.47 g) followed by IC-0599709 (826.77 g) whereas, it was minimum in AHK-119 (72.20 g) followed by AHLM-2 (81.63 g). Arya-1 resulted in maximum fruit length $(29.70 \mathrm{~cm})$ and it was minimum in AHK-119 $(6.33 \mathrm{~cm})$. Fruit diameter ranged from $2.10-11.27 \mathrm{~cm}$ being minimum in AHLM-2 and maximum in IC-0599709. The fruits of Pusa Madhuras had highest flesh thickness $(2.60 \mathrm{~cm})$ and AHK-119 had lowest $(0.87$ $\mathrm{cm})$. AHK-119 produced maximum number of marketable fruits per plant (24.27) followed by AHLM-2 (20.33) whereas; it was minimum in Pusa Madhuras (2.47). The maximum TSS was recorded in IC-0599709 (11.30\%) and minimum in AHK-119 (2.90\%).

Significant difference was observed among the intraspecific $\mathrm{F}_{1}$ hybrids of Cucumis melo group (Table 2). Among the crosses, AHLM- $2 \times$ IC-0599709 took minimum days to produce $50 \%$ pistillate flowering (47.67 days) followed by AHLM- $2 \times$ Arya-1 (49.00 days). AHLM- $2 \times$ Arya-1 was found to be earliest in first fruit harvest (54.87 days) followed by AHLM-2 $\times$ AHS-82 (55.07 days) and AHLM- $2 \times$ IC-0599709 late in harvesting (84.00 days). The maximum fruit weight was recorded in AHLM-2 $\times$ IC-0599709 (1142.00 g) followed by AHS-82 $\times$ AHLM-2 $(979.00 \mathrm{~g})$ whereas, it was minimum in AHLM-2 $\times$ AHS-82 (76.40 g) followed by AHLM-2 $\times$ Arya-1 (77.00 g). AHS-82 $\times$ AHLM-2 resulted in maximum fruit length $(53.80 \mathrm{~cm})$ while it was minimum in IC-0599709 $\times$ Pusa Madhuras $(10.43 \mathrm{~cm})$. The cross AHLM-2 $\times$ IC-0599709 had maximum fruit diameter $(12.03 \mathrm{~cm})$ followed by IC-0599709 $\times$ Punjab Sunehri $(11.90 \mathrm{~cm})$ and AHLM-2 $\times$ AHS82 had minimum $(1.97 \mathrm{~cm})$. Flesh thickness varied from $1.23 \mathrm{~cm}$ in AHS- $82 \times$ AHLM-2 and IC$0599709 \times$ Punjab Sunehri $(3.07 \mathrm{~cm})$. The cross, AHK-119 $\times$ Kashi Madhu produced maximum number of marketable fruits per plant (16.40) followed by AHLM-2 $\times$ AHS-82 (10.00) whereas it was minimum in IC-0599709 $\times$ Punjab Sunehri (4.00). The maximum TSS was observed in IC0599709 x Pusa Madhuras (11.27\%) followed by IC-0599709 $\times$ Punjab Sunehri $(9.73 \%)$ and minimum in AHK-119 $\times$ Kashi Madhu (6.10\%). All evaluated intraspecific $\mathrm{F}_{1}$ hybrids of Cucumis species showed monoecious sex expression. The morphology of the hybrids was generally intermediate between their parental varietal forms. Earlier several researchers observed great variability in melons and characterized the landraces of muskmelon (Sheshadri and More 2002, Choudhary et al. 2012), snapmelon (Dhillon et al. 2008) and melons (Sheshadri and More 2002, Malik et al. 2014).

The fruits of the $\mathrm{F}_{1}$ hybrids of IC-0599709 $\times$ Punjab Sunehri, IC-0599709 $\times$ Pusa Madhuras, AHK-119 $\times$ Kashi Madhu, AHLM-2 $\times$ IC-0599709, AHS- $82 \times$ AHLM-2 and AHS-82 $\times$ AHK119 were found bitter at immature stage and become edible at full ripening stage. Among the dessertic $F_{1}$ hybrids, IC-0599709 $\times$ Punjab Sunehri resulted best with respect to earliness which took 73.33 days to first fruit harvest, fruit weight $(938.00 \mathrm{~g})$, fruit diameter $(11.90 \mathrm{~cm})$, flesh thickness $(3.07 \mathrm{~cm})$ and salmon orange coloured flesh. $\mathrm{F}_{1}$ hybrid C-0599709 $\times$ Pusa Madhuras gave maximum TSS $(11.27 \%$ ) but it was found to be at per with IC-0599709 $\times$ Punjab Sunehri (9.73\%). Splitting of fruits at ripening stage was observed in AHLM- $2 \times$ IC-0599709 and AHS-82 $\times$ AHLM-2. AHLM- $2 \times$ AHS- 82 and AHLM- $2 \times$ Arya -1 produced fruits free from bitter principle at tender stage and can be used as salad purpose. The crosses made utilizing $C$. melo var. utilissimus $\times$ C. melo var. momordica and C. melo var. utilissimus $\times C$. melo var. chate resulted in dessertic type fruits which were free from bitter principle at tender stage. The $F_{1}$ hybrids derived from $C$. melo var. callosus $\times$ C. melo, $C$. melo var. utilissimus $\times$ C. melo, $C$. melo var. momordica $\times$ C. melo var. utilissimus and $C$. melo var. momordica $\times$ C. melo var. callosus produced dessertic type of fruits which were bitter at tender stage and became edible at ripening stage. A very limited study has been made on intraspecific hybridization utilizing different varietal forms of C. melo $\mathrm{L}$. 


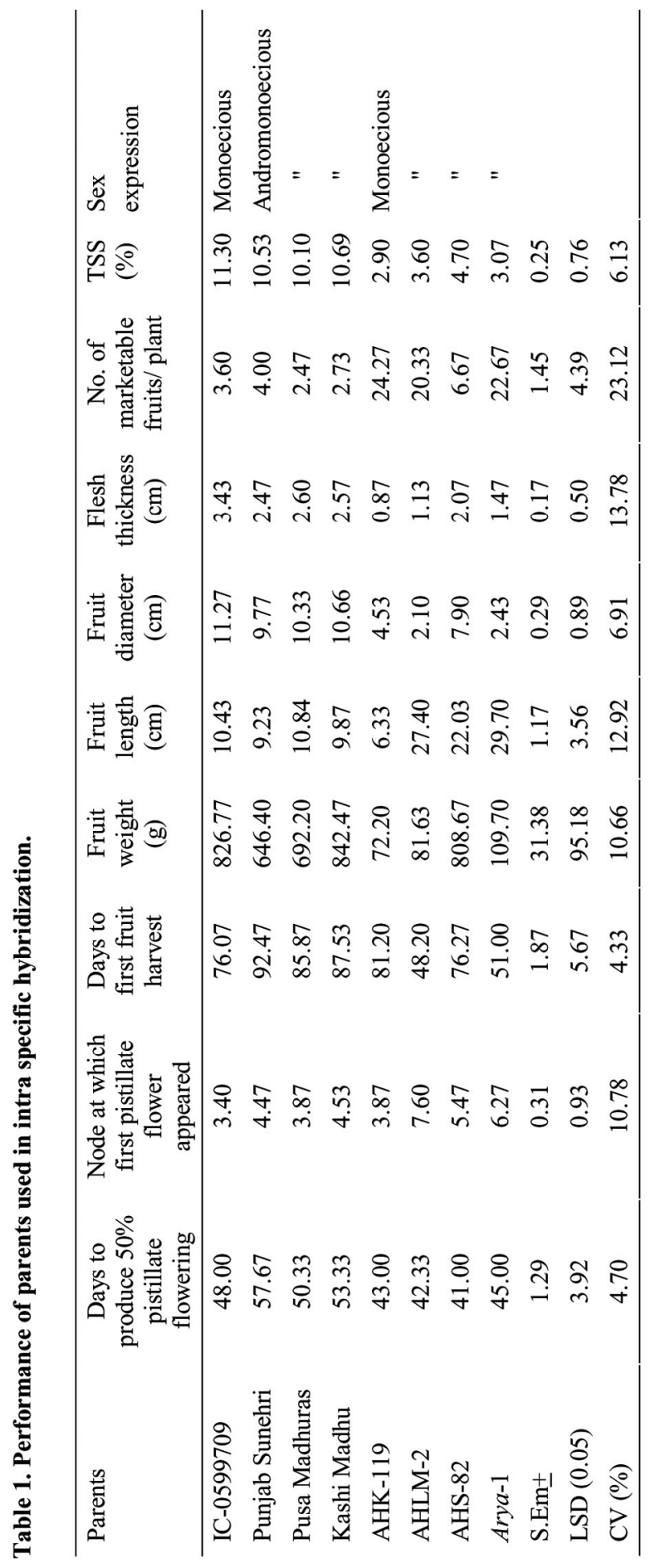




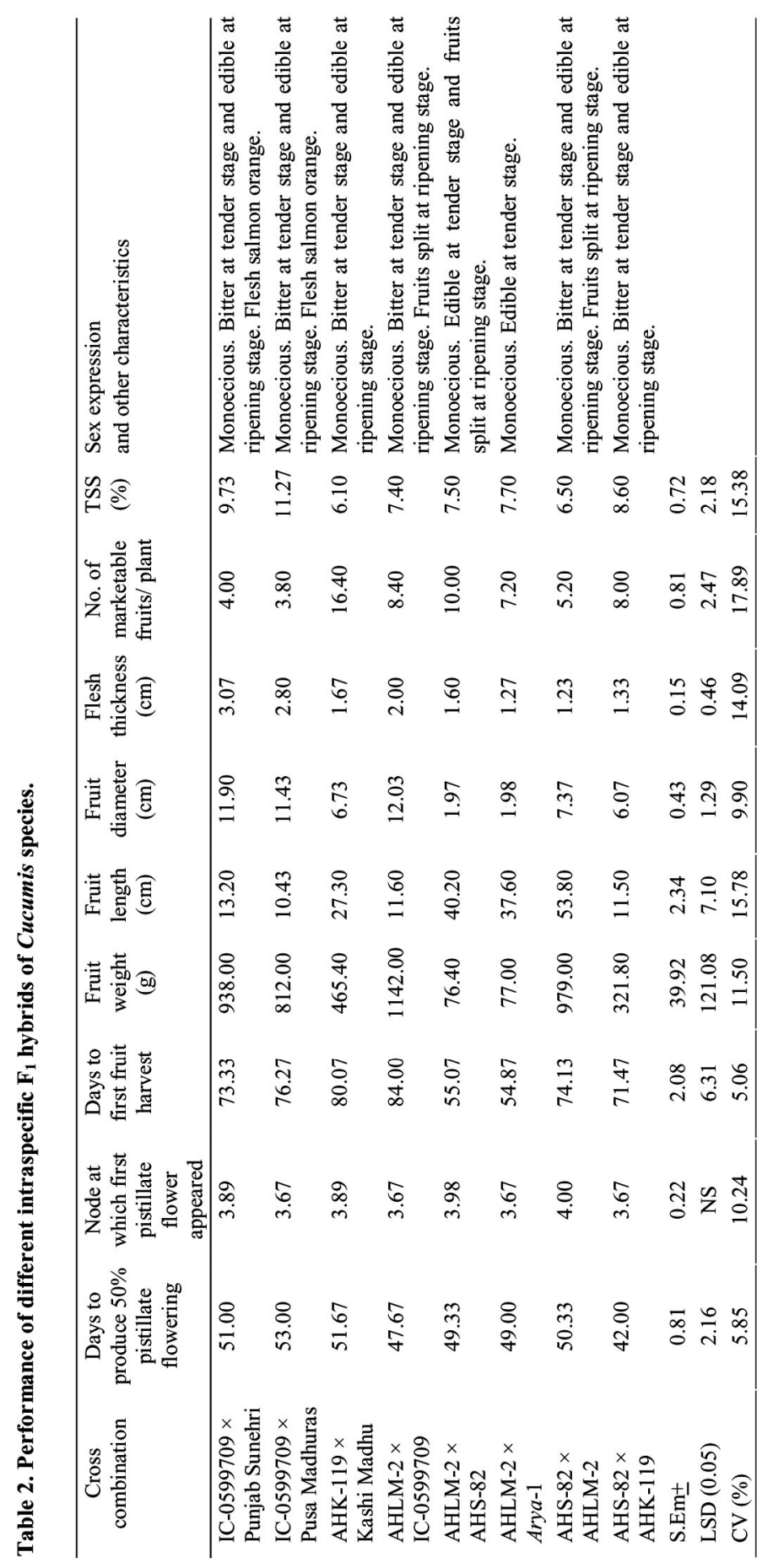




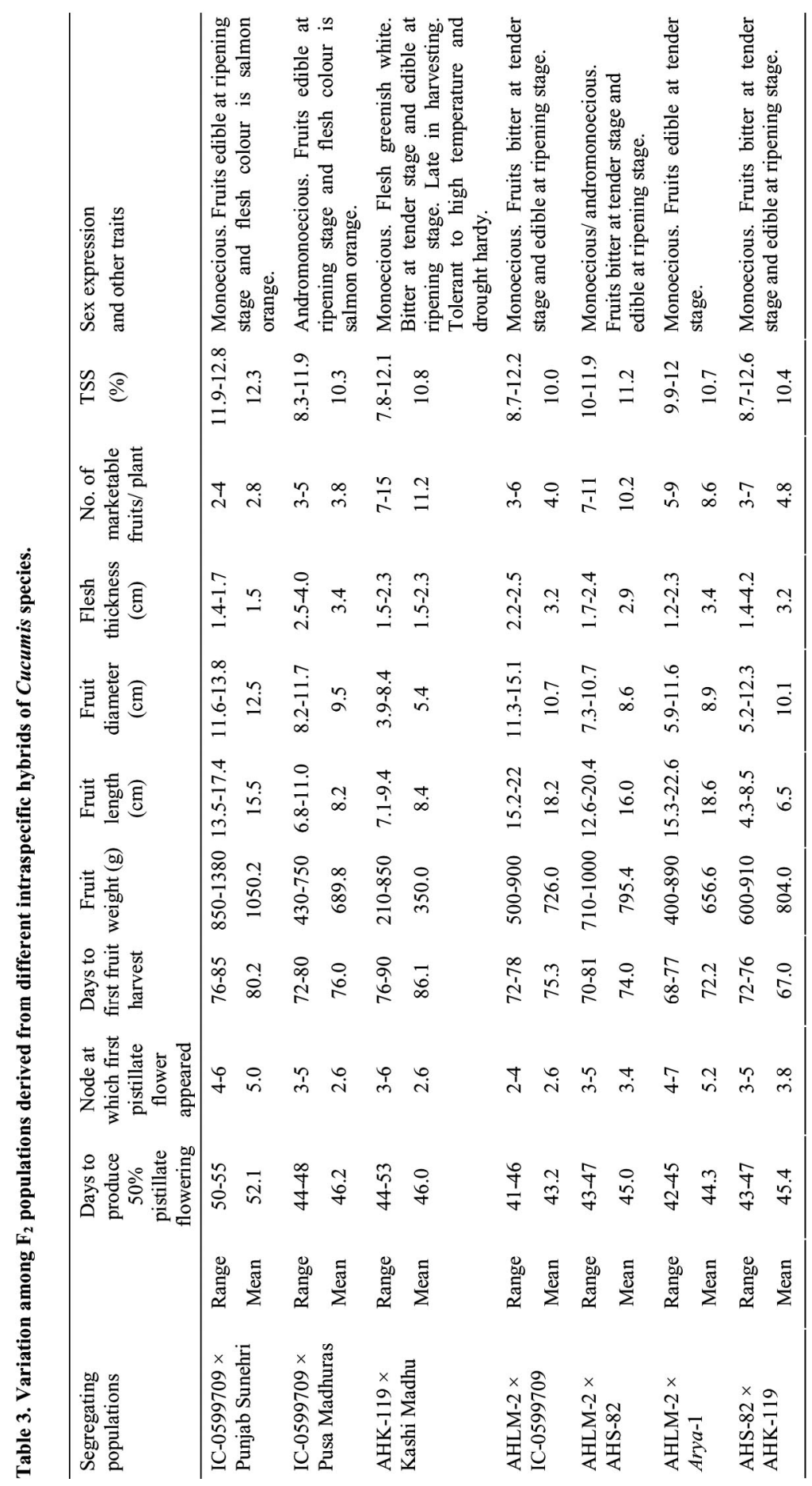


Nath and Dutta (1971) attempted intraspecific crosses among muskmelon, snapmelon and longmelon. Singh et al. (2013) reported Vellari (C. melo var. acidulous) $\times$ Tibish melon $(C$. melo var. tibish) as the best cross for nutritional quality and maximum consumer preference. Pandey et al. (2010) hybridized different varietal form of $C$. melo L. and observed significant heterosis for the number of marketable fruits per plant, and ascorbic acid and carotenoid content in marketable fruits in the hybrid derived from longmelon $($ C. melo var. utilissimus $) \times$ tibish $($ C. melo var. tibish $)$ and longmelon $(C$. melo var. utilissimus) $\times$ Punjab Wanga (unknown botanical variety).

Considering the existing great variation among the intraspecific crosses of Cucumis melo group in fruit (size, shape, colour), yield and quality parameters segregating populations were developed to explore the possibilities of new desirable segregants. Evaluated seven segregating populations of $\mathrm{F}_{2}$ generations of Cucumis species for different horticultural traits and observed wide variability. The mean data and range of flowering, fruit, yield, quality and sex expression have been presented in Table 3. Among the evaluated $\mathrm{F}_{2}$ populations, AHK-119 $\times$ Kashi Madhu produced maximum number of marketable fruits per plant (11.2) weighing $350.00 \mathrm{~g}$ however it was late in harvesting ( 86.1 days). It was also found to be tolerant to high temperature.

The selected generations were advanced through inbreeding to develop inbred lines having desirable traits. Pandey et al. (2011) studied the $599 \mathrm{~F}_{2}$ population derived from an intraspecific cross between Kashi Madhu (C. melo L.) and B-159 (C. melo var. momordica) to establish intertrait relationship among the traits and developed recombinant inbred lined for QTL mapping for horticultural traits and total soluble solids. The results obtained will further be useful in classification studies of Cucumis species.

\section{References}

Choudhary BR, Haldhar SM, Maheshwari SK, Bhargava R and Sharma SK 2015. AHMM/BR-8 (IC0599709; INGR 1403), a muskmelon (Cucumis melo L.) germplasm with monoecious sex form. Indian J. Plant Genet. Resour. 28: 357-358.

Choudhary BR, Kumar S and Sharma SK 2012. Genetic variability and inter-trait association in muskmelon (Cucumis melo L.) under arid conditions. Crop Improv. 473-474.

Dhillon NPS, Ranjana R, Singh K, Eduardo I, Monforte AJ, Pitrat M, Dhillon NK and Singh PP 2007. Diversity among landraces of Indian snapmelon (Cucumis melo var. momordica). Genet. Resour. Crop Evol. 54: 1267-1283.

Jeffery C 1980. A review of the Cucurbitaceae. Botanical J. Linn. Soc. 81: 233-247.

Malik AA, Vashisht VK, Singh K, Sharma A, Singh DK, Singh H, Monforte AJ, McCreight JD and Dhillon NPS 2014. Diversity among melon (Cucumis melo L.) landraces from the Indo-Gangetic plains of India and their genetic relationship with USA melon cultivars. Genet. Resour. Crop Evol. 61: 1189-1208.

Munger HM and Robinson RW 1991. Nomenclature of Cucumis melo L. Cucurbit Genet. Coop. Rpt. 14: 4344.

Nath P and Dutta OP 1971. Hybridization among muskmelon, snapmelon and longmelon. Indian J. Hort. 28: 123-129.

Pandey S, Dhillon NPS, Sureja AK, Singh D and Malik AA 2010. Hybridization for increased yield and nutritional content of snake melon (Cucumis melo L. var. flexuosus). Plant Genet. Resour: Charact. Utiliz. 8: 127-131.

Pandey S, Singh PK, Singh S, Jha A and Raghuwanshi R 2011. Inter-trait relationship and variability in segregating population of muskmelon derived from intra-specific cross for total soluble solids and yield. Indian J. Plant Genet. Resour. 24: 52-55.

Sheshadri VS and More TA 2002. Indian land races in Cucumis melo. Acta Horticulturae 588: 187-193.

Singh AK, Jha A, Dhillon NPS and Pandey S 2013. Increasing yield and quality of indigenous melons by combining intraspecific group of Cucumis melo. Prog. Hort. 45: 335-339. 
Stepansky A, Kovalski I and Perl-Treves A 1999. Intraspecific classification of melons (Cucumis melo L.) in view of their phenotypic and molecular variation. Plant Syst. Evol. 217: 313-332.

Whitaker TW and Davis GN 1962. Cucurbits. InterScience, New York. 250.

(Manuscript received on 9 September, 2018; revised on 4 January, 2019) 